\title{
INFORMAL NETWORKS: MANAGING THE KNOWLEDGE WITHIN VIRTUAL ENTERPRISES
}

\author{
Tonia Marta Macedo \\ PhD student at Université de Droit, d'Économie et des Sciences d'Aix-Marseille III \\ Macedotm@hotmail.com \\ FRANCE \\ Ruben José Naveira \\ PhD student at Universidade Federal do Rio de Janeiro - COPPEUFRJ \\ Ruben@novanet.com.br
}

BRAZIL

Either within conventional or virtual enterprises, the capacity of processing information efficiently has been viewed as a new competency for organizations. Some studies on communication in Science \& Technology highlight the interactive exchanges of information and knowledge among individuals. The effectivity of these informal networks to fulfill their own information needs points out the importance of the human processing of information, not only to $S \& T$ but also to organizations in general.

\section{INTRODUCTION}

Despite the great impact of information technology within conventional and virtual enterprises, managing the collaboration in the context of a complex and changing world is far beyond the development of technological cooperation tools.

The relationships that people develop within organizations is recognized today as part of the work itself as some authors point out the importance of knowledge communities or communities of practice (Lave \& Wenger,1991) and informal networks in organizations (Krackhardt \& Hanson, 1997).

The challenge now for organizations is the understanding of how people interact in a collaborative manner, facing technological dimension - as the electronic cooperation tools - and the human dimension - as communication and trust in networks. 


\section{INFORMAL COMMUNICATION AND NETWORKS}

Reviewing the literature on the role of human networks on information processing in organizations, Grosser (1991) verifies that organizations that operate in complex environments must seek out supplementary or alternative communication channels, indicating the importance of recognizing informal channels in organization contexts, despite their formal structures.

Confronted with the formal organization - very efficient in dealing with predicted problems - the informal organization - by its own nature, highly adaptive - is capable of responding better than the former to unpredicted problems (Krackhardt \& Hanson,1997).

A few studies present a typology of informal networks in organizations. Krackhardt \& Hanson (1997) make a distinction between trust networks where politically sensitive information is shared; advice networks - which involve the utilization of the informal structure for contacts between individuals who have technical information that facilitates meeting work goals; and communication networks - of individuals who exchange, regularly, work information. Roberts and O'Reilly McClure apud McClure (1978), distinguish social networks - for subjects not related to work; authority networks - for communications relative to authority and responsibility between members of the organization, and expert networks for technical information.

Despite these typologies, studies on management information sources show that the majority of their information come from direct human contact (Grosser,1991). Direct contact is still the fastest and most efficient way of having access to information - overcoming problems of excessive information and aggregating value to the whole set through rich and significant interpretations of their contents.

\section{COMMUNICATION IN SCIENCE AND TECHNOLOGY}

Informal networks that scientists establish among themselves is essential for scientific knowledge. The final product - the published work - is not only the result of the several agencying and translations that occur within their laboratories, as already shown by Callon's studies (1989), in the area of science's anthropology, but also from the series of information and knowledge informally exchanged within support networks that the various scientific communities consolidate along time.

In the 60's, Price (1963) used the term "invisible college" to describe informal communities of scientists, that, communicating and meeting periodically to exchange information and experience, began to perform a fundamental role for the formal publication and dissemination of advancements in the field of scientific knowledge:

Cronin apud Gresham (1984) observes that the advantages of the invisible colleges, in contrast with the more formal channels of academic communication, concern how updated information are, the opportunity of feedback and sharing of stages that form the development of an idea and to 
the interdisciplinary transmission of ideas, pointing out that these "colleges" emerge around major researchers.

Interpersonal communication is part, therefore, of scientists' work in developing their activities. Regardless of data availability and of the easiness for access to information that several technological developments provide, personal interaction - either face to face or computer mediated (keeping their singularities) - occupies a relevant role in providing momentum and intensifying information flows required to their research. Direct consultation to peers to share doubts, to learn new developments and to reduce equivocality is inherent to work with knowledge.

As this work with knowledge increasingly overtakes the frontiers of laboratories and invades, at least while at a level of speech, the terrain of organizations in a general way, the way through which knowledge workers for excellency - the scientists - equate their information problems can serve as a paradigm to provide parallels and analogies that can be useful for other contexts in which knowledge has a relevant role.

\section{THE INVISIBLE PLAYERS: GATEKEEPERS}

Studying informal communication in scientific and technological research laboratories in the 60's, Allen (1984) identified the "technological gatekeepers" - individuals who, from their degree of exposure to information sources external to their organization, for their knowledge and professional and personal connections outside their close work community, represent a vital information role within their work group, both as information and as "internal consultants" - for the capacity of technical discussion and expertise.

A study of Holland apud Vieira (1998) on the characteristics of the "gatekeepers" role in the scientific community of research and development government organizations showed: a unique receiver and transmitter of information. Not only is a productive member of the organization, but, as well, is a vital and stimulating link for his colleagues; an extender and amplifier of information research for all those with whom he makes exchanges. When he gets involved in an information research, his greater network of professional contacts allows him to open more doors and to involve a greater number of potential information sources.

It has been observed that in the "invisible colleges", comprising geographically spread scientists, there are individuals who also act as the gatekeepers studied by Allen. Grosser (1991) argues that the key specialists, although geographically dispersed, perform the same type of role as do technological gatekeepers within one organization.

Not restricting, thus, to their physical space, even though proximity is indeed an important cohesion factor for establishing their informal networks, the importance of gatekeepers extends to the set of configurations of information exchanges necessary to work with knowledge, going beyond geographical conditioning factors and increasingly receiving impacts from available information technologies. 


\section{Gatekeepers in Organizations}

Although a great part of classical studies on informal communication is turned to scientific and technological communities, which deal intensively with the construction of knowledge - while, more recently, the subject is the object of an increasing interest from the literature on management - a few generalizations have been made; for instance, by Tushman \& Scanlan (1981), who applied Allen's concept of technological gatekeeper to other organizations, studying the role of certain individuals - "boundary-spanning" - in information transfer and in importing strategic information for organizations.

Allen himself (1984) verifies that the phenomenon of the gatekeeper is one example of a general class of phenomena.

Studying the role of these individuals who, in organizations in general and not only in scientific communities, are naturally capable of acquiring, processing and using information, it was verified that, although they receive several denominations - "information specialists", "internal consultants", "experts", "technological gatekeepers" - they have in common, among other things, thefact that they know where to obtain information, both from informal, formal and semi-formal sources, and are capable of filtering them to transmit just what is relevant from outside the organization to the group with which they interact, performing a kind of current-awareness (McClure, 1978).

Thus, similarly to technological gatekeepers in the scientific and technological communities, there are individuals within organizations who develop a network of internal and external contacts and contribute for other individuals' work in their personal contact circle. Due to their characteristics of technical competence and as link elements, they are important sources of information and new ideas, occupying a relevant role in the informal network.

Making an analogy with the invisible colleges of the scientific communities, it is possible to think that organizations - conventional or virtual and independently of their geographical or divisional distribution and in parallel to their formal configuration - are also constituted by "invisible networks" where gatekeepers, not exclusively technological, perform a relevant role on human processing of information and on the organization's information flows.

If a great part of studies on informal networks have shown the importance of the role of central players - the gatekeepers, for instance - for information processing, Krackhardt \& Hanson (1997) believe that the continuity of these studies shall occur through mapping such networks, what can allow the organization to increase its efficiency.

One of the benefits from this mapping would be the identification of communication gaps where strong relationships should be desirable. This suggests that, if the incentive to these interactions could not assure on a first moment the formation of the necessary relations, the continuous exposure to them increases the possibility of its occurrence, what would increase the organization's performance (Krackhardt \& Hanson, 1997). 


\section{THE ELECTRONIC VISIBILITY OF INFORMAL NETWORKS}

According to Lévy (1993), information technologies are part of the history of intellectual technologies, which participate in a fundamental way in the cognitive process because intellectual processes do not involve just the mind, they put into play complex things and technical objects having a representative function and the operational automation that accompany them. For Lévy (1993), similarly to the society of primary orality - in a certain stage of the human history - the word represented, through myths, the possibility of inserting into the mind of individuals the codification of certain knowledge; that writing represented and still represents an essential role in establishing science as a dominant knowledge mode, information technology - through the integration of several media under various applications, software and platforms - inserts itself in the set of forms of available knowledge.

In this sense, electronic communication, as a subset of information technologies, does not restrict itself to be a simple reproducer of messages within informal networks, but a true actant ${ }^{1}$ of the knowledge construction and dissemination process. Crossing structures and hierarchies, computer mediated electronic communication establishes not only new time and space relations, but new standards of social relations that, in turn, create other forms of knowledge production and circulation.

\section{Electronic Mail and Electronic Conferences}

Electronic mail and conferencing, from have recently been the object of several studies with the intent of evaluating their roles in organizations and in scientific communities (Carley \& Wendt, 1991; Rojo \& Ragsdale, 1997)

Empirically studying the role of electronic communication, Bishop (1992) researched the impacts of using electronic conferencing in the work of aerospace engineers in several American States. According to answers received, she pointed out, among others, the following aspects: 1) they allow ideas and problems to be expressed according to needs; 2) they allow for the fast solution of problems; 3 ) they distribute available "expertise" to all employees; 4) they make possible to answer quickly to changes; and 5) increase commitment and team work.

Both in the environment of science and of organizations, in general, electronic communication overcomes barriers which limit information flow. The use of electronic mail and conferencing, however, has not the intent of replacing other informal communication media. Depending on the subject, on the geographical proximity and on how one needs feedback, the face to face interaction and the telephone can be preferred or complement the utilization.

This possibility of a media to offer feedback is associated, partially, to what a few authors call media richness, a perspective which assumes implicitly that a media has inherent characteristics that make it more or less effective (Wiesenfeld, Raghuram \& Garud, 1998). Daft, Lengel \& Trevino apud Garton \& Wellman (1993) relate this richness to the capacity of a media 
to support multiple cues (similar to the social presence), helping participants to understand each other through feedback, variety of language and personal focus, what includes emotions and feelings (contrarily to a lean media, which is supported by rules, forms and procedures).

A more recent view, however, expands this concept, suggesting that, additionally to the inherent properties of the media, the social context should be inserted in order to determine its true impact on individuals (Markus apud Wiesenfeld, Raghuram \& Garud, 1998). In this sense, regardless of the face to face interaction to be more appropriate in conditions of low structured and ambiguous tasks, since determined utilization standards are established, less rich media can incorporate more significance than if they are being used in less specific contexts (Vieira, 1998). This way, e-mail, for instance, can be rich as a function of the extension with which message emitters and receivers share their organizational contexts.

This more relativist perspective in relation to the "richness" of media maybe explains the fact that informal electronic communications, either through the utilization of mail, or through conferencing, occupies an increasing importance in the scientific and technological communities and organizations, both for the possibility of storing and accumulating information and knowledge - the example being formal communication and for the opportunity of sharing the set of contents and contexts of ideas the example being face to face interactions.

From an organizational learning point of view, Blantern, Murphy \& Boydell (1997) have highlighted that sharing what is learnt across contexts requires both lean (structured databases - content) and rich or 'informal' media (chat/discussion - process).

In the last years, a set of technological solutions based on these principles were placed in the market, to create mechanisms to apprehend the knowledge dispersed by the organization, mobilizing monitoring activities and facilitating innovation processes. Known as knowledge tools which use, among other things, the concept of rich media - like e-mail and electronic conferencing, in comparison to products that just manage data and information - they worry about the capacity of the organization to capture the complexity and richness of knowledge, contributing to its generation, codification and transfer. ${ }^{2}$

Despite the features of these tools in respect to the constitution of "knowledge bases" and their electronic visibility, it is necessary to reinforce the understanding that their simple existence does not alter the fact that these bases have a nature essentially different from the databases or information bases.

In this sense, to make these tools available to an organization does not create the environment in which knowledge can be transferred in all its complexity. For this, it is necessary that they are part of a set of "hybrid" relations that include relationship networks or informal networks that constitute the environments where this transfer occurs.

The example of how Xerox utilized the technology in the 1980s and early 90s to augment knowledge work is paradigmatic in this sense. According to Ruggles (1997), Xerox discovered that copier repair technicians 
have congregated in common areas, trading stories, transferring their knowledge and expertise among themselves. The management realized that these activities were part of being a good "tech rep", it was how they formed bonds as community. Meshing of technological capabilities with the reps social and behavioral norms, Xerox created an eletronic knowledge product called Eureka which organized and categorized a database of tips generated by the reps.

The experience of Xerox in building its knowledge base has shown that the availability of a technological tool, in itself, regardless of how aligned it is with the state of the art of technology and information, is not sufficient to resolve and address all questions related to information processing in organizations.

As Ruggles (1997) concludes, only when proper technologies are used together with effective practices - and this involves not only the capacity to create but of observing already existing practices - the organization can make their professionals, individual and collectively, to take the best advantage from their knowledge.

This approach configures not the fragmentation commonly used of subjects who use technology or of technologies which "adapt" subjects, but of subject-technology sets that are part of the relationship network, the effects of which can be or not positive to the very professionals and organizations.

\section{CONCLUSIONS}

In an economic order in which knowledge is more and more considered as an "infra-structure", there is not the possibility of not recognizing the importance of informal networks or organizational "invisible colleges" as part of the instruments necessary to solve problems that the knowledge society imposes, not simply as fixed structures with given roles, but as configurations that already participate of the knowledge management that fulfills their own interests.

What must be pointed out, however, is that a) there are knowledge contents that circulate through these networks and that can be useful to organizations without fundamentally interfering on their structures and b) there are elements within these networks, the gatekeepers, who can be useful because they are naturally gifted with the capacity of processing information.

In this view, it seems necessary to highlight the subjective aspects of the collaboration - either within conventional or virtual organizations observing it in the context of the daily work. The social forms of association and its informal dynamics respond for an effective information processing. These informal dynamics that exist as heterogeneous networks comprising human and non-human actors - as electronic cooperation tools - are hybrid configurations capable of facing the challenges of a changing and not predictable world. 


\section{NOTES}

1. Callon (1989: 173-214) uses this notion from semiotics to designate humans and nonhumans that act within networks.

2. See Knowledge Space (http://www.knowledgespace.com) and Lotus Notes (Available on http://www.lotus.com, consulted on 03.02.1999).

\section{REFERENCES}

1. Allen, TJ. Managing the Flow of Technology: technology transfer and the dissemination of technological information within the R\&D organization. Cambridge: MIT Press, 1984.

2. Bishop, AP. Eletronic Communication in Engineering Work. American Society for Information Science (ASIS) 1992; 29:193-205.

3. Blantern, C, Murphy, A, Boydell, T. Using Networked IT for Organizational Learning in conditions of distributed power, knowledge \& purpose, 1997 (http//www.eclo.com /conferences/1997/ b03.htm, consulted on 25.01.1999).

4. Callon, M. "L'Agonie d'un laboratoire". In La science et ses réseaux, Michel Callon, org. Paris: Éditions La Decouverte, 1989.

5. Carley, K, Wendt, K. Electronic Mail Scientific Communication - A Study of the Soar Extended Research Group. Knowledge: Creation, Diffusion, Utilization 1991; 12 (4): 406-441.

6. Garton, LE, Wellman, B. Social Impacts of Electronic Mail in Organizations: A Review of the research literature, 1993. (http://www.dgp.utoronto.ca/tp/papers/9313.html, consulted on 11.03.1999).

7. Gresham, JL. From Invisible College to Cyberspace College: Computer Conferencing and the Transformation of Informal Scholarly Communication Networks. Interpersonal Computing and Technology: An Eletronic Journal for the 21 Century 1994; 2 (4): 37 52. (http:// www.lib.ncsu.edu/stacks/i/ipct/ipct-v2n04-gresham-from.txt, consulted on $02 / 02 / 1999$ ).

8. Grosser, K. Human Networks in Organizational Information Processing. Annual Review of Information Science and Technology (ARIST) 1991; 26:349-402.

9. Krackhardt, D, Hanson, JR. "Informal Networks: The Company". In Knowledge in Organizations, Laurence Prusak. S.L.: Butterworth-Heinemann, 1997.

10. Lave, J, Wenger, E. Situated Learning: Legitimate Peripheral Participation. Cambridge, U.K.: Cambridge University Press, 1991.

11. Lévy, P. As tecnologias da inteligência: o futuro do pensamento na era da informática. São Paulo: Editora 34, 1993.

12. McClure, CR. The Information Rich Employee and Information for Decision Making: Review and Comments. Information Processing \& Management 1978; 14: 381-394.

13. Price, DJS. Little Science, Big Science. New York: Columbia University Press, 1963.

14. Rojo, A, Ragsdale, RG. A Process Perspective on Participation in Scholarly Electronic Forums. Science Communications 1997; 18, 4: 320-341.

15. Ruggles, R. Knowledge Tools: Using Technology to Manage Knowledge Better, 1997 (http://www.businessinnovation.ey.com $/ \mathrm{mko} / \mathrm{html} /$ toolsrr.html, consulted on 25.01.1999)

16. Tushman, ML, Scanlan, TJ. Boundary Spanning Individuals: Their Role in Information Transfer and Their Antecedents. Academy of Management Journal 1981;24,2: 289-305.

17. Vieira, JLG. Correio eletrônico: o impacto na comunicação técnico-científica da EMBRAPA. Rio de Janeiro: UFRJ/ECO; CNPq/IBICT, 1998. (Master of Degree Dissertation).

18. Wiesenfeld, BM, Raghuram, S, Garud, R. Communication Patterns as Determinants of Organizational Identification in a Virtual Organization. Journal of Computer-Mediated Communication 1998; 3 (4). (http:// jcmc.mscc.huji.ac.il /vol3 /issue4 /wiesenfeld.html, consulted on 12.03.1999). 